\title{
Food security and agriculture in the Western Highlands of Guatemala
}

\author{
Santiago Lopez-Ridaura ${ }^{1} \cdot$ Luis Barba-Escoto ${ }^{1} \cdot$ Cristian Reyna $^{2} \cdot$ Jon Hellin $^{3} \cdot$ Bruno Gerard $^{1} \cdot$ Mark van Wijk $^{4}$
}

Received: 9 March 2018 / Accepted: 26 May 2019 / Published online: 20 July 2019

(C) The Author(s) 2019

\begin{abstract}
Food security is a major challenge in Guatemala, one of the poorest countries in the world. Food insecurity is concentrated in the Western Highlands of Guatemala (WHG) where indigenous communities have been the main victims of social, political and economic marginalization. In this study we characterize the diversity of farming households in the WHG, identify the main sources of food for different types of farm households and assess their food security status through a simple, yet robust, potential food availability indicator. Based on a large and rich dataset of nearly 5000 farm households, our results show the diversity of farming systems in the region, dominated by maize and coffee production, as well as the large differences in their potential food availability. In our model, 52\% of farm households in the WHG did not have the means to attain sufficient energy from their agricultural activities. In general, diversified maize-based, coffee-based and specialized coffee farm households had larger proportions of potentially food secure households with $60 \%, 83 \%$ and $74 \%$ food secure households, respectively. This contrasted with farm households specialized in maize production and resource-constrained households where there were a greater proportion of households were food insecure. The analytical framework presented here, combining a typology of farm households and their livelihoods with the analysis of their food security status, provides a useful approach for better targeting development interventions towards combating hunger, poverty and malnutrition.
\end{abstract}

Keywords Guatemala $\cdot$ Food insecurity $\cdot$ Farm typologies $\cdot$ Food availability indicator $\cdot$ Maize $\cdot$ Coffee

\section{Introduction}

Uneven progress towards food security remains an intractable development challenge, and will continue so for decades to come. Sub-Saharan Africa has received most attention on this

Electronic supplementary material The online version of this article (https://doi.org/10.1007/s12571-019-00940-z) contains supplementary material, which is available to authorized users.

Santiago Lopez-Ridaura

s.1.ridaura@cgiar.org

1 Sustainable Intensification Program, Centro Internacional de Mejoramiento de Maíz y Trigo (CIMMYT), km 45 Carretera México-Veracruz, El Batán, 56130 México City, Mexico

2 Doctorado en Ciencias Biológicas y de la Salud, Universidad Autónoma Metropolitana Xochimilco (UAM-X), México City, Mexico

3 Socio-Economics Program, Centro Internacional de Mejoramiento de Maíz y Trigo (CIMMYT), México City, Mexico

4 International Livestock Research Institute (ILRI), Quito, Ecuador topic, but achieving food security remains a challenge in other parts of the world. In Guatemala, rural poverty and food insecurity are endemic. The World Food Program ranks Guatemala as the country with the highest level of child undernutrition in the western hemisphere and the fourth highest level in the world (WFP 2018). The International Fund for Agricultural Development (IFAD 2011) indicates that approximately $70 \%$ of the impoverished population lives in rural areas, where agricultural production is the main livelihood activity and source of food. Poverty and malnutrition are especially prevalent amongst indigenous communities, which comprise $38 \%$ of the total population. These communities are mainly concentrated in the Western Highlands of Guatemala (WHG), and historically have suffered from discrimination leading to structural exclusion, social inequality and violence (Steinberg and Taylor 2008). In 2010, the United States Agency for International Development (USAID) launched a strategy to address poverty and chronic malnutrition in Guatemala. The strategy document specifically highlighted the concentration of poverty and malnutrition in the WHG (USAID 2013).

Food security in the WHG is, as in many rural areas of the world, a complex, multifaceted phenomenon where farm 
households are, at the same time, producers and consumers of food, and their livelihoods rely on both agricultural and nonagricultural activities. This is especially the case in the WHG because of high population density and limited land availability: $62 \%$ of households in the region have less than 0.7 ha of arable land and $85 \%$ have less than 1.4 ha (MAGA 2011). Faced with limited land availability, farm households in the WHG have had to find alternative sources of food and income. These include daily agricultural labor on nearby farms, handcraft production (notably weaving), construction work, national and international migration (either seasonal or permanent) and, for the more fortunate, small businesses and waged jobs. Despite these multiple sources of income, agriculture is still the most important livelihood strategy for the majority of the population in the WHG and the backbone of local food security (IFAD 2011).

The study presented here characterized the diversity of farm households in the WHG, assessed their food security status, and identified the main agricultural activities that contribute to this security. We address the following research questions. 1) What are the key farming activities and farm types in the WHG? 2) What is the relationship between these different farming types and their agricultural-determined food security? 3) Are there systematic patterns in the occurrence of these farm types and their associated levels of food security that can help agencies to better target interventions aimed at improving agricultural production and food security in the region? By answering these questions we also evaluated the analytical framework used to identify farm types, quantify food security and discuss whether our approach is good enough to generate useful information for targeting interventions.

\section{Methods}

\subsection{Study area and data used}

We used data from the baseline survey "Encuesta de Monitoreo y Evaluación del Programa del Altiplano Occidental (EMEPAO)", conducted by USAID and Guatemala's Ministry of Health and Social Assistance (MSPAS) between July and November 2013 as part of USAID's Feed the Future Program (Angeles et al. 2014). The survey targeted 6301 households in 55 municipalities that belong to the departments of Totonicapán, San Marcos, Quiche, Quetzaltenango and Huehuetenango in the WHG (Fig. 1). The EMEPAO survey included information on household characteristics, their assets and living conditions, their participation in cooperatives or farmers associations, as well as the technical support received. The survey also included expenditure incurred by the household for all kinds of goods and services as well as detailed information on cropping and livestock activities. The sample included participating and non-participating households in the USAID rural value chains program, and was randomly selected within the delimited national census sectors. See Angeles et al. (2014) for more details on the sampling process, survey tool and application. After removing households with no agricultural activity or with inconsistent data (e.g. maize cultivated on more land than total land available), data from 4790 households were included in the analysis.

\subsection{Typology of farmers based on principal component analysis-clustering}

We based the farmer typology on a statistical multivariate analysis process (Alvarez et al. 2014; Tittonell et al. 2010). Typologies are only a snapshot of the current farm diversity situation, and therefore the variables we chose as discriminant variables were structural, or slow moving, variables in the overall dynamical regime (Berre et al. 2016). We sought to represent, from a systemic perspective, farm household diversity in terms of the available resources (land and livestock) as well as the main agricultural activities, including cash crops, food crops, livestock or mixed crops-livestock (Berre et al. 2016). We selected 25 variables from the survey for the construction of the farming systems typology; these variables characterize households in terms of the family household size, land availability, area allocated to each crop, crop diversity, multi-cropping practices and livestock rearing (Tables 1 and 2).

When inspecting data, some variables with low variability (e.g. Most households had 5 to 6 household members) or very infrequent values (e.g. Fewer than $5 \%$ had small ruminants), were left out for the principal component analysis (PCA) or used to calculate other aggregated variables (e.g. Density - number of household members over arable land-, or TLU- that aggregates all livestock into a Tropical Livestock Unit-). A correlation analysis was also performed and only one for the highly correlated variables $\left(\mathrm{R}^{2}>0.8\right)$ was selected for the PCA so as to avoid giving too much weight to one dimension of the farming system. We eventually chose eight variables for the PCA. These variables describe farm households in terms of available arable land and density (in relation to household size), crop diversification as well as land area allocated to key crops, and livestock production (Table 1). The remaining 17 variables were used, together with the eight core variables, to describe the different farm household types (Table 2).

Maize is the main staple crop in WHG followed by potato at higher elevations. Coffee is the main cash crop, but farmers also grow a diversity of cash crops for local, national and export markets. The share of the available arable land dedicated to these crop activities (i.e. maize, potato, coffee, and other crops) was used in the typology construction. For livestock holdings, animal numbers in the household were converted into Tropical Livestock Units (TLU) using the conversion 


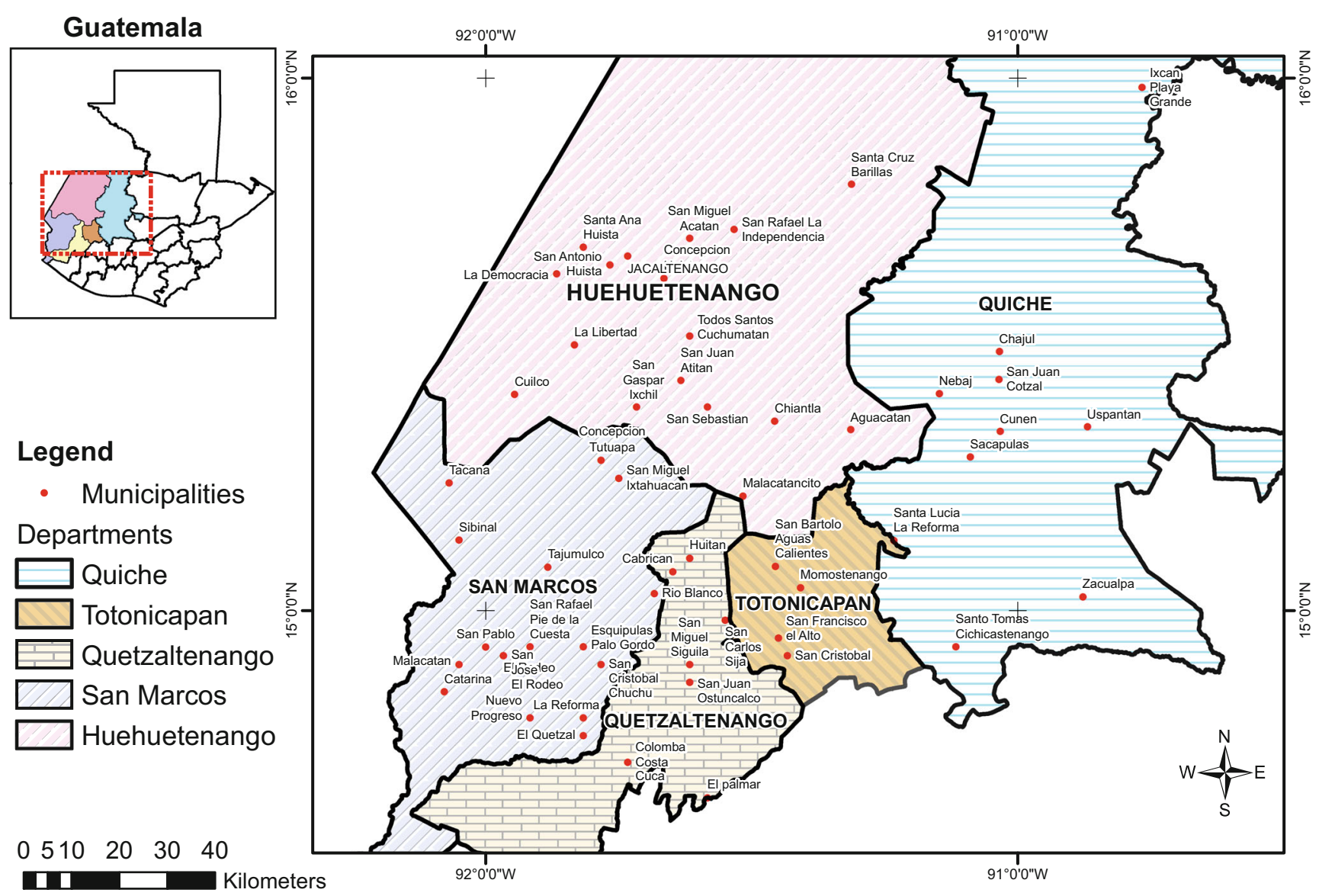

Fig. 1 Municipalities in the Western Highlands of Guatemala surveyed in the "Encuesta de Monitoreo y Evaluación del Programa del Altiplano Occidental (EMEPAO)"

factors: cattle $=0.7$, pigs $=0.2$, sheep $/$ goats $=0.1$ and chicken $=0.01$. Data on income sources (i.e. on, off, non-farm income) were not available and therefore were not included in the characterization of farming systems.

We performed all analyses and computations in $\mathrm{R}(\mathrm{R}$ Development Core Team 2018). Correlation analysis was

Table 1 Variables used for the farm households typology construction in the Western Highlands of Guatemala

\begin{tabular}{lllll}
\hline Variable & Acronym & Mean & Median & IQR \\
\hline Density (persons/ha) & DENSITY & 25.2 & 11.5 & 19.1 \\
Total arable land (ha) & TAL & 0.7 & 0.5 & 0.7 \\
Number of crops grown (\#) & CROPSN & 2.5 & 2 & 2 \\
Land on maize (\%) & LOM & 51.9 & 50 & 58.3 \\
Land on coffee (\%) & LOCOFF & 23.9 & 0 & 44.6 \\
Land on potato (\%) & LOPOT & 1.7 & 0 & 0 \\
Land on others (\%) & LOO & 8.9 & 0 & 5.6 \\
Tropical livestock units & TLU & 0.5 & 0.2 & 0.7 \\
IQR: inter quartile range & & & & \\
\hline
\end{tabular}

performed with the cor and corrplot functions and packages, PCA analysis with the prcomp, and k-means clustering with kmeans function (stats package). The relevant selection criteria for PCs was through the Scree plot test (Cattell 1966). The PCA coordinates were then used to construct a $k$-means clustering, based on the Hartigan and Wong (1979) algorithm, which partitions points into $k$ groups in such a way that the 'Within Group Sum of Squares' (WGSS) from points to the assigned cluster centers is minimized. Alternatively, raw values can be used for creating clusters, but we found that i) a similar number of groups was generated and ii) more significant differences between groups were obtained when using the PCA coordinates.

The clusters' centers are defined as the mean of a set of data points based on their coordinates. The number of clusters, $k$, was established combining the elbow method and the interpretation of the resulting clusters in relation to meaningful farm diversity. The elbow method consists of running the $k$ means algorithm on the data set for a range of values of $k$ (clusters or groups number) and then, for each $k$, the within groups sum of squares (WGSS) is calculated and the number 


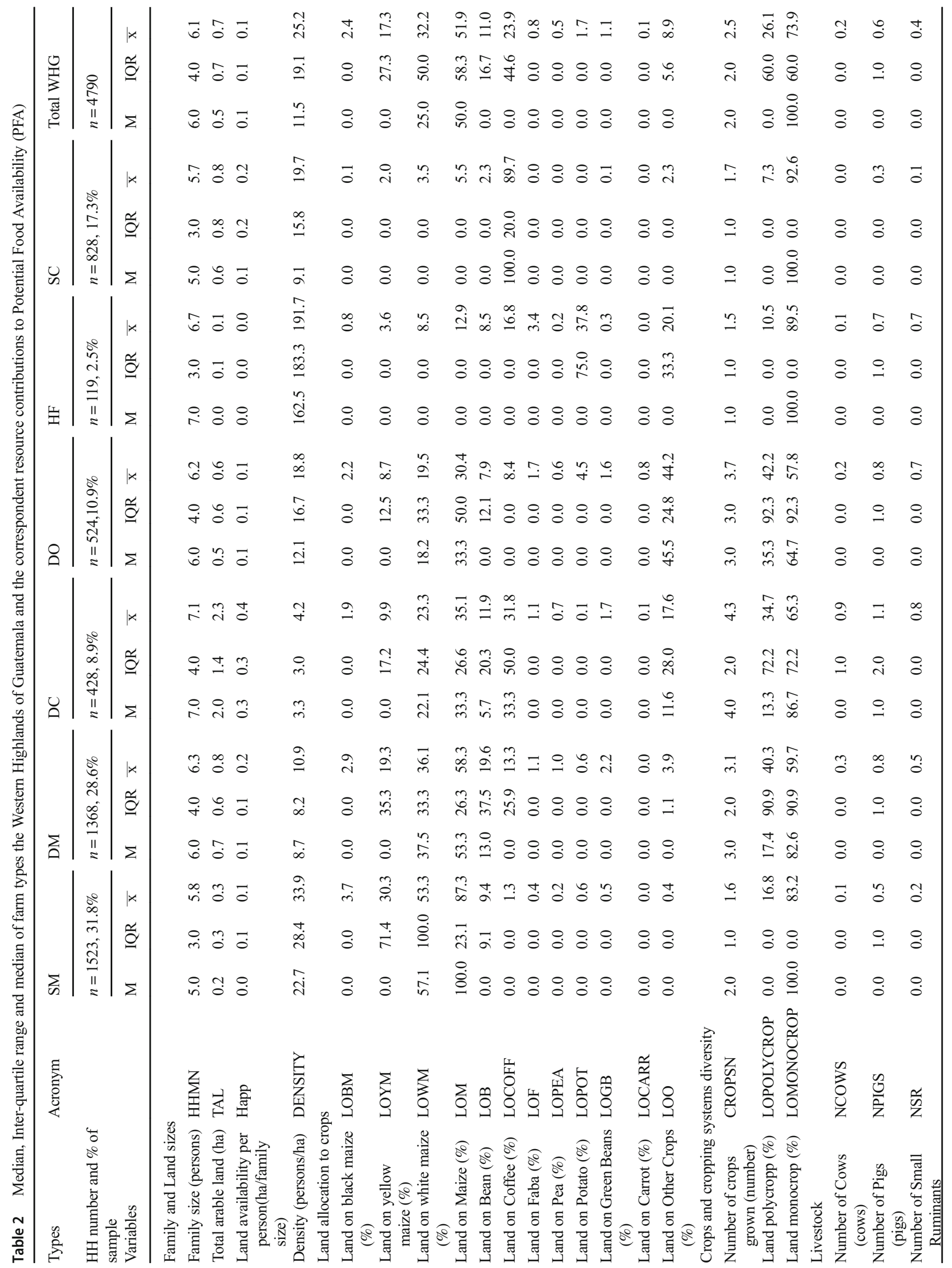




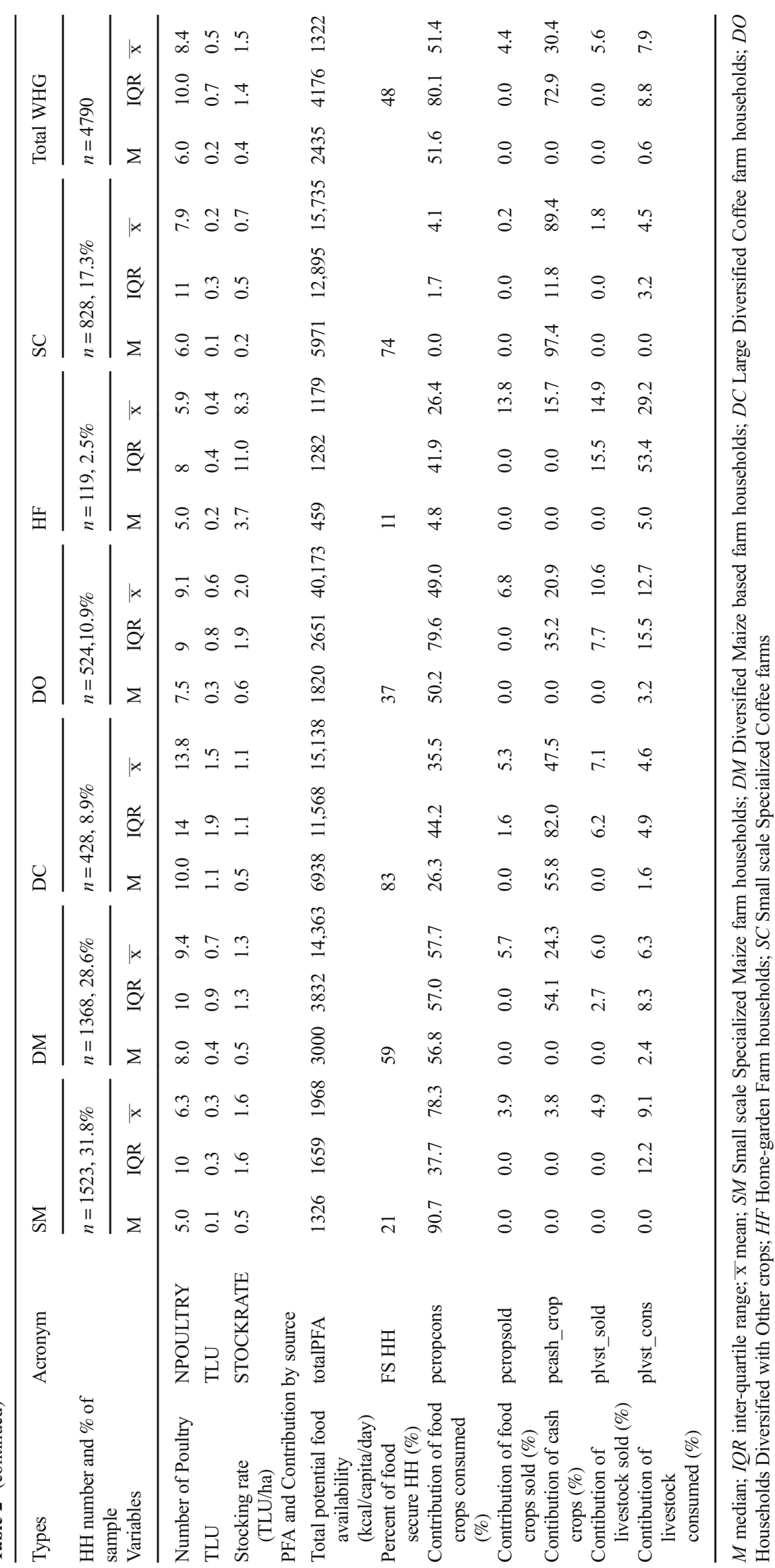


of groups with a low number of $k$ optimized which minimizes the WGSS (Hartigan 1975; Kassambara 2017).

\subsection{Food availability Indicator}

Food security is defined as everyone having continued access to a sufficient quantity and quality of food (FAO 2003). Four dimensions of food security have been defined: availability, access, utilization and stability (FAO 1996). Here we focus on the food availability dimension by applying the model of Potential Food Availability (PFA) at the household level from Frelat et al. (2016) (Fig. 2) that quantifies the potential food availability as an index calculated on the basis of daily kilocalories per individual. Farm products are converted to kilocalories either if households consume these products directly or sell them. In the case of sold products, we converted the income into potential staple food that farmers can theoretically buy and, in turn, we converted this into kilocalories. The kilocalories potentially bought and consumed are summed and, hence, correspond to total potential food availability per year. The household's energy requirements per year are calculated based on the composition of the household's members (Frelat et al. 2016) (Fig. 2).

Detailed testing of the food availability indicator (e.g. Frelat et al. 2016; Hammond et al. 2017) showed that it is well related to other indicators of food security (e.g. the Household Food Insecurity Access Scale, number of months with hunger and the Household level Dietary Diversity Score) when agricultural production and off-farm income are constraining food security. In more intensive agricultural systems, the correlation is less robust and the indicator does not function well. Further validation of this simple indicator is presented here

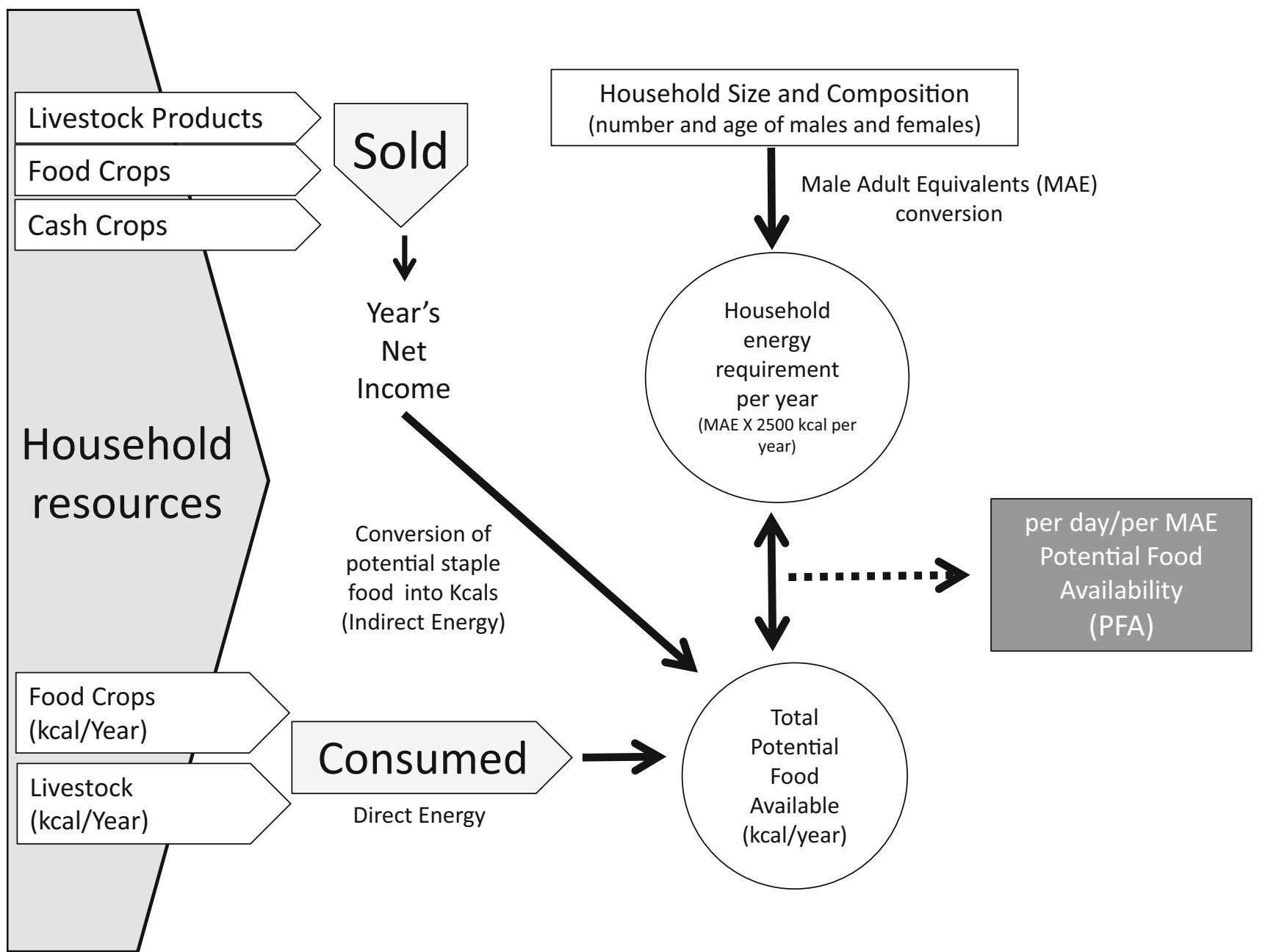

Fig. 2 Model representation of household food availability expressed as kcal. Energy is derived from direct on-farm products that households consume and the transformation of the products' sale income into potential staple food purchase and its conversion into calories. The availability is based on male adult equivalents (MAE).The PFA, expresses that when it is $\geq 2500$, the household has enough or more Potential Food Availability than needed per day per family member and is in consequence food secure. If the ratio is $<2500$, the household energy requirements is larger than potential food availability and thus the household is food insecure. Based on Frelat et al. (2016) 
by correlating the output of the PFA indicator with binary variables of the sample related to food, which are described in detail after the description of the model.

The quantification of the indicator is based on the household members' potential acquisition of kilocalories on a yearly basis by direct consumption of on-farm products and indirectly by the conversion of cash from product sales into staple food. The direct Potential Food Availability $\left(\mathrm{PFA}_{\text {direct }}\right)$ acquisition (i.e. consumed produce) by households in kilocalories is determined by crop and livestock derived energy:

$P F A_{\text {direct }}=\sum_{f C} Y_{f c} \times E_{f c} \times C_{f c}+\sum_{l} Y_{l} \times E_{l} \times C_{l}$

Where: fc denotes a certain food crop, and 1 a certain livestock, $\mathrm{Y}$ represent the production or number of animals or quantity of products (eggs, milk, meat, etc.) for fc or 1, E denotes the energy (kcal kg-1) content of each animal or food crop product, and $\mathrm{C}$ denotes the proportion of $\mathrm{Y}$ consumed by household. Energetic coefficients for crop and livestock products were determined from USDA (2015) values, while the production and consumption proportions are based on survey information.

Indirect energy acquisition by households $\left(\mathrm{PFA}_{\text {indirect }}\right)$ is a function of the potential quantity of staple food that can be bought by means of income derived from selling farm produce, expressed in calories. The Cash by Income in Quetzales $\left(\mathrm{CI}_{\mathrm{Q}}\right)$, the national currency, derived from farm produce sales, was defined as:

$$
C I_{Q}=\sum_{f C} Y_{f c} \times P_{f c} \times\left(1-C_{f c}\right)+\sum_{l} Y_{l} \times P_{l} \times\left(1-C_{l}\right)
$$

Where $P_{f c}$ and $P_{l}$ denote the median market price per kilogram, reported by survey respondents, of a certain crop or animal product respectively, and where the term $(1-\mathrm{C})$ denotes the proportion of farm product not consumed directly either from crops or livestock. Cash crops are defined as those where farmers sell more than $90 \%$ of the total annual production. With the available cash, farmers buy staple food, which in this region is maize, at the median value of the market prices reported in the survey $\left(\mathrm{S}_{\text {price }}\right)$. Using the metabolic energy content of one $\mathrm{kg}$ of maize $\left(\mathrm{E}_{\text {maize }}\right) \mathrm{PFA}_{\text {indirect }}$ is then calculated as:

$P F A_{\text {indirect }}=\frac{C I_{Q}}{S_{\text {price }}} \times E_{\text {maize }}$

The total amount of food potentially available $\mathrm{PFA}_{\text {total }}$ for households is then defined as:

$P F A_{\text {total }}=P F A_{\text {direct }}+P F A_{\text {indirect }}$

On the energy needs side we used household composition, gender and age to calculate total household energy requirement ( $\mathrm{E}_{\mathrm{hhr}}$ ). According to FAO (2001), a male adult has a daily need of $2500 \mathrm{kcal}$ to sustain a fine nutrition with average daily activity. Humans have different energy requirements depending on age and gender. Hence, we took each household and assigned each member a male adult equivalent (MAE) according to the following ranges, new born: 0.29 , children $1-3$ years: 0.51 , children $4-6$ years: 0.71 , children $7-10$ years: 0.78 , males $11-$ 14 years: 0.98 , males $15-18$ years: 1.18 , males $19-50$ years: 1.14 , males $>51$ years: 0.9 , females $11-50$ years: 0.86 , females $>51$ years: 0.75 . Daily $E_{\text {hhr }}$ is calculated as:

$$
E_{h h r}=2500 \sum_{i} M A E_{i}
$$

Considering the above calculations, we can define the Potential Food Availability (PFA) as:

$P F A=\frac{P F A_{\text {total }}}{E_{h h r} \times 365_{\text {days/year }}}$

which quantifies how much energy per capita per day is potentially available.

For validation of the results from the PFA indicator, we first made classes of the farm household in relation to their PFA. The classes were based on distribution of PFA in quartiles from the overall sample. Then, we used two questions in the survey to examine the validation of the PFA model. Question 1 - "In the last month, was there at some point no food because of lack of resources?" $29.2 \%$ of those interviewed responded 'yes'. The second question was "In the last month, have you gone to sleep without eating because of lack of food?" to which $10.5 \%$ of the respondents said 'yes'. A chi-squared test was performed to see if the distribution of affirmative and negative responses was correlated with the PFA results.

In addition, crossing PFA classes based on quartiles and types was performed applying a chi-squared test to see if specific patterns arise among farm types and the PFA indicator in order to identify the type of farmers who are most food insecure. Thus, through an analysis of their PFA profile, i.e. understanding the contribution of different agricultural activities for different farm types, specific interventions to enhance their food security can be defined.

\section{Results}

\subsection{Diversity of farming systems in the Western Highlands of Guatemala}

Farms in the WHG are largely small-scale maize-based farming systems. The median land available per household was 0.5 ha and, with median size of household of six members, the median density was 11.5 members per ha. Main crops grown included maize, beans, coffee, potato and a large diversity of other crops for both home consumption and markets. A median of $50 \%$ of the land was devoted to maize, mainly 
produced for home consumption. Potato is both a staple and cash crop in the higher elevations of the WHG. The most important cash crops in the region were coffee followed by green bean, faba bean, and pea. Average number of crops managed by rural households in the WHG was 2.5 and polyculture (i.e. maize intercropped with beans, potato, faba bean, etc.) is a common practice with an average of $26 \%$ of the land managed under this system. In terms of livestock activities, most families had poultry (77.8\%) and pigs (36.3\%); only $9.2 \%$ of farm households reared small ruminants and $9.8 \%$ had cows (Table 2).

Three first PCA axes had eigenvalues above $1(1.94,1.67$ and 1.25 ) and the percent variance explained by each of them was $\mathrm{PC} 1=24.3, \mathrm{PC} 2=20.5$ and $\mathrm{PC} 3=15.7$. The cumulative variance explained by all three was $60.5 \%$ (Fig. 3a). We used the variable scores for each principal component $(\mathrm{PC})$ axis and the spatial distribution of these scores in the PCA space to differentiate the households. Figure $3 \mathrm{c}, \mathrm{d}$ and e show the eight variables selected for the typology definition, as well as the individual farm households, projected against the three PCA axes. The proportion of land under coffee (LOCOFF), as well as the land under maize (LOM), were important variables, differentiating farm-households in the dataset. The density or land available per capita and the number of crops grown were also important. Farm size (total arable land (TAL)) was important for identifying resource rich households. On the other side of the PCA space the number of crops grown (CROPSN) and, to a certain extent, the land under potato (LOPOT) and other crops (LOO) allowed us to identify diversified farming systems that were based on crops other than coffee or maize.

The optimum number of clusters $k$ according to the elbow method is $k=6$ (Fig. 3b). The number of households and their percentage in the total sample are for cluster one, 119 households forming $2.5 \%$ of the total sample; cluster two, 1523 households (31.7\%); cluster three, 828 households (17.2\%); cluster four, 428 households ( $8.9 \%$ ); cluster five, 524 households (10.9\%); and cluster six 1368 households (28.6\%).

Based on this PCA-Clustering analysis, we identified six distinctive types of farm households. Differences between these types were mainly determined by the amount of land available and the share of land used for maize or coffee production. The six types were small scale Specialized Maize farm households (SM); Diversified Maize based farm households (DM); small scale Specialized Coffee farmer (SC); large Diversified Coffee
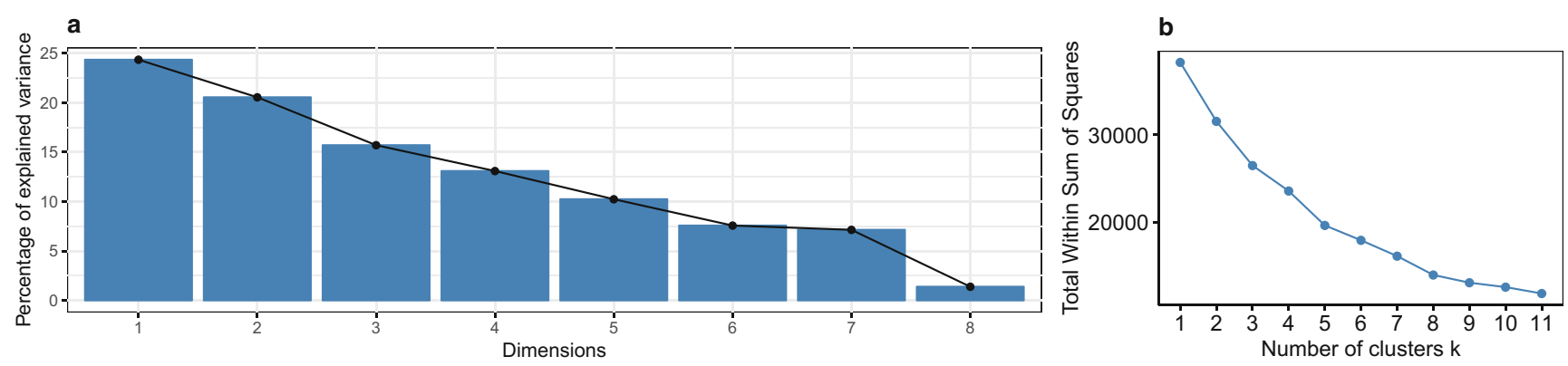
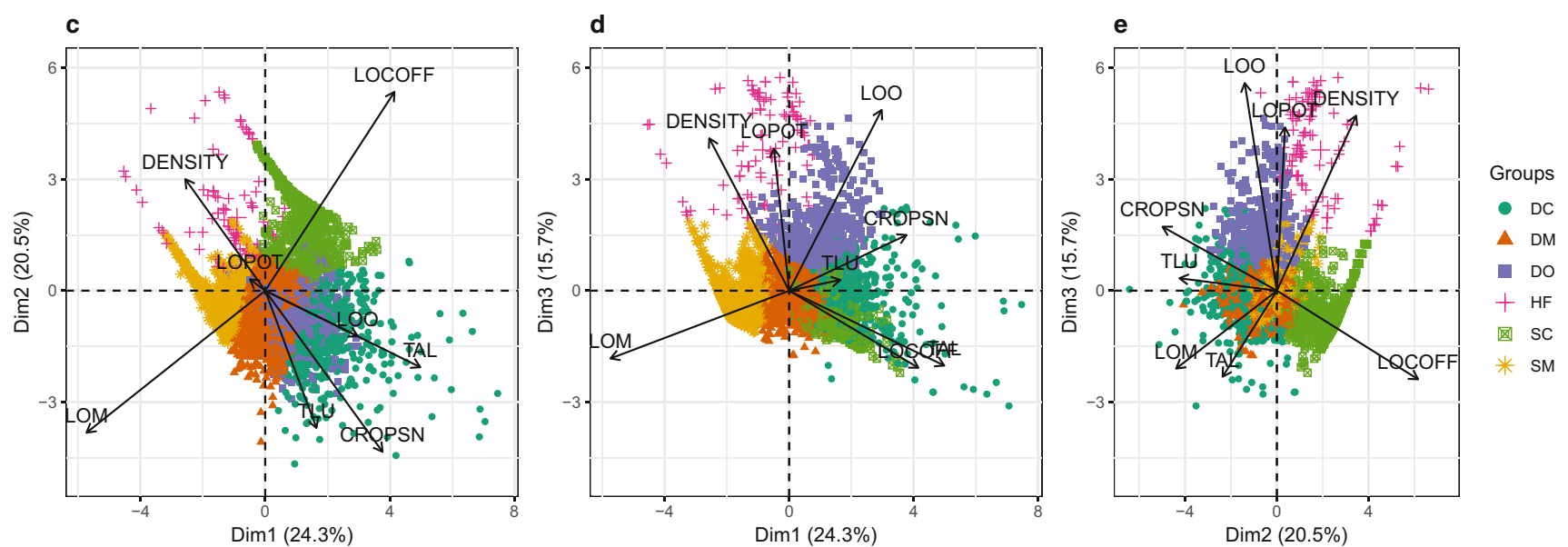

Fig. 3 a Scree plot . b Total within group sum of squares (WGSS) criterion defined the optimal number of k-groups, the optimum k-WGSS is reached at $\mathrm{k}=6$. $\mathbf{c}, \mathbf{d}$ and $\mathbf{e})$ the households, grouped by type and projected into bi-dimensional principal component planes. c PC1-PC2, d PC1-PC3 and e) PC2-PC3. DENSITY: density (persons per ha), TAL: total arable land, LOCOFF: land on coffee, LOM: land on maize,
LOPOT: land on potato, LOO: land on other crops, CROPSN: Number of crops grown, TLU: tropical livestock units. SM: Small scale Specialized Maize farm households, DM: Diversified Maize based farm households, DC: Large Diversified Coffee farm households, DO: Households Diversified with Other crops, HF: Home-garden Farm households, SC: Small scale Specialized Coffee farms 
farm households (DC); Home-garden farm households (HF) and households Diversified with Other crops (DO).

Small scale specialized maize farm households (SM) The SM households type covered $31.8 \%$ of the total sample and were characterized by a median arable land available of 0.2 ha per farm household mainly devoted to the production of maize (median of 100\% of surface under maize, mainly in monocrop but sometimes sown together with beans). The livestock holdings in these households, mainly poultry, was the second lowest of the types with a median of 0.1 Tropical Livestock Units (TLU) (Table 2).

Diversified maize based farm households (DM) The DM type of households ( $28.6 \%$ of the sample) had larger arable land available (median of 0.70 ha) compared to SM, with half of it devoted to maize production (land under maize, median 53.3\%), mainly under the traditional intercropping system called milpa where maize is grown together with beans, squash and several other crops (mean of $40.3 \%$ of maize or other crops surface grown under intercropping systems). The remaining $59.7 \%$ was devoted to a large diversity of crops: mainly beans and coffee, but also faba bean, green pea, other vegetables, and in some cases potato. The median value of number of crops per farm household was three. In terms of animals, this type was very similar to SM households, with a slightly higher number of poultry (Table 2).

Small specialized coffee farmer (SC) The SC household type constituted $17.3 \%$ of the farm households. Median land available was 0.6 ha per farm household and they were mainly specialized in the production of coffee. This was the type with the lowest diversity of crops grown (median of 1.0) and with little land devoted to maize (less than 5\%). The coffee grown, as well as the maize, were produced as monocrops (100\%). Livestock holdings in these farms were small, with a median holding of 0.1 TLU (Table 2).

Households diversified with other crop (DO) The DO group covered $10.9 \%$ of the total sample and had a median arable land area of 0.6 ha. DO farmers had a high diversity of crops grown (median of 3.7), and the largest proportion of land allocated to other crops (mean 45.5\%) including potato, coffee, maize and other crops. DO farmers had the largest proportion of land allocated to poly-crops (median $35.3 \%$ ) (Table 2).

Large diversified coffee farm households (DC) The DC farm households, $8.9 \%$ of the total sample, were characterized by relatively larger land holdings (median of $2.0 \mathrm{ha}$ ). Coffee occupied nearly the same share of land (median of $33.3 \%$ of the total land available) as maize (median
$33.3 \%$ ), followed by $11.6 \%$ of land under other crops. These farms also had the largest diversity of crops (with a median value of four crops grown per household). This type of household showed above average livestock holdings with poultry, pigs and large ruminants present (livestock holdings median value of 1.1 TLU per household) but, with its large landholding showing the lowest stocking rate (median $0.5 \mathrm{TLU} / \mathrm{Ha}$ ) (Table 2).

Home-garden farm households (HF) The HF type of household formed $2.5 \%$ of the total population. These farmers had very small land holdings with a median value of 0.04 ha per household. Farmers used available land to grow specific crops, notably potato, with little diversity (median of number of crops grown per household was 1.0). These farmers had chickens and small ruminants, and because of their small land holdings, households of this group showed the highest stocking rate (median 3.7 TLU/Ha) (Table 2).

\subsection{Food security Indicator}

The contribution of agriculture to the Potential Food Availability (PFA) for the farm households in the WHG varied from almost no contribution to more than ten times the kcal needs for the family (Fig. 4a). For more than half of the households (52\%), agricultural production did not meet the kcal needs of the family and therefore farmers need other sources of food/income (e.g. off-farm income, remittances from family members working in the United States of America). The contribution of energy by consumption of farm-produced food crops was relatively low, but is of significant importance in households with low PFA. The absolute contribution from consumption of farm-produced food crops increased as PFA increases, but only up to a certain point and for households with higher levels of PFA, it decreased again (Fig. 4a).

Full food self-sufficiency was never reached from own produced crops, with market orientation taking off when farm households were able to produce between 50 and $70 \%$ of their food needs. This section of maximum PFA was characterized by households in which sales of cash crops contributed most to PFA, while also sales of food crops in general increased with increasing PFA. Livestock did contribute to PFA of households with low PFA scores, although the contribution was not major, and thereby play a complementary role in the consumption of food crops. As the PFA value of households becomes larger, energy coming from livestock consumption or livestock sales becomes larger as well. However, for households with the higher PFA values, cash crops were more important and the role of livestock became small (Fig. 4a, b).

We defined four food security classes by partitioning the 4790 households into quartiles: i) the NEFA (Not Enough Food Available) class encompasses those households with 

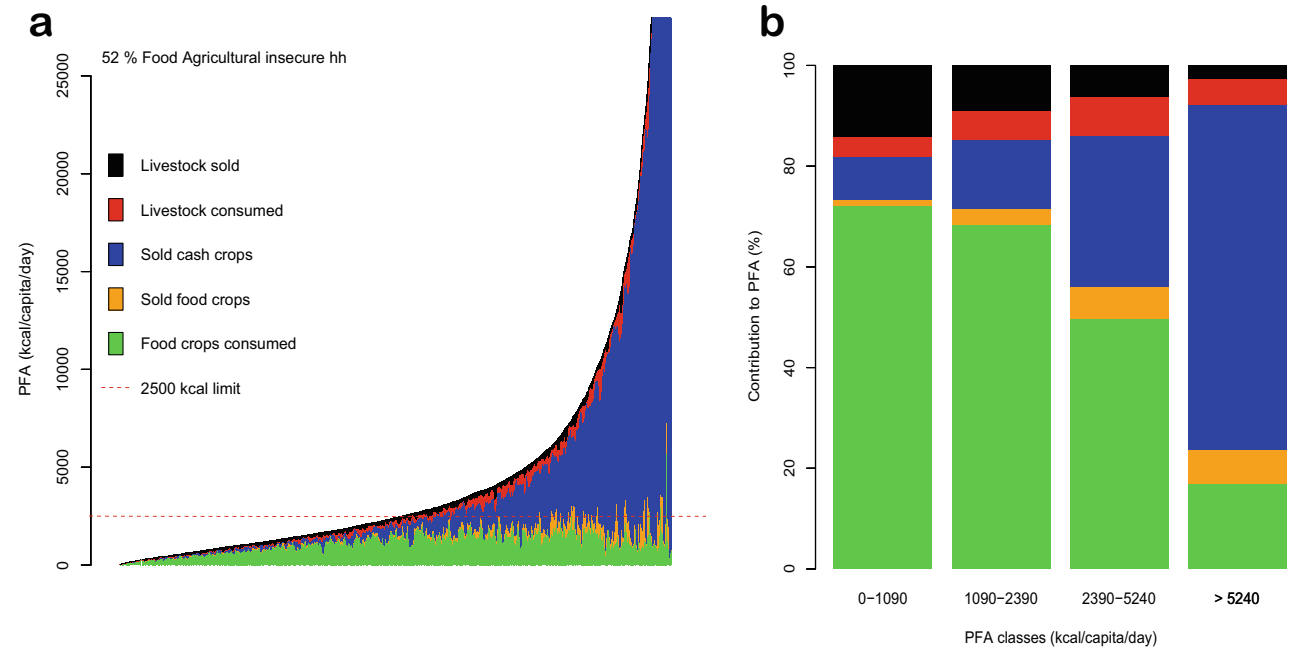

Fig. 4 a Potential food availability (PFA) among 4790 households from the EMEPAO-WHIP survey in the Western Highlands of Guatemala. Farm households are ordered from low to high PFA values. The red dashed line indicates the $2500 \mathrm{kcal} / \mathrm{capita} /$ day $(\mathrm{PFA}=1)$. Legend colors

PFA below $1090 \mathrm{kcal} / \mathrm{capita} / \mathrm{day}$; ii) the REFA class (Roughly Enough Food Available) with those where the PFA value falls between 1090 and $2390 \mathrm{kcal} /$ capita/day; iii) the SFA class (Sufficient Food Available) with between 2390 and $5240 \mathrm{kcal} / \mathrm{capita} /$ day and finally iv) the MEFA class (More than Enough Food Available) $>5240 \mathrm{kcal} /$ capita/day. For both the NEFA and REFA classes, the average PFA scores do not meet the daily kcal requirements of the household with agricultural activities. For the first three quartiles, the most important contributor to the PFA indicator was the consumed own-

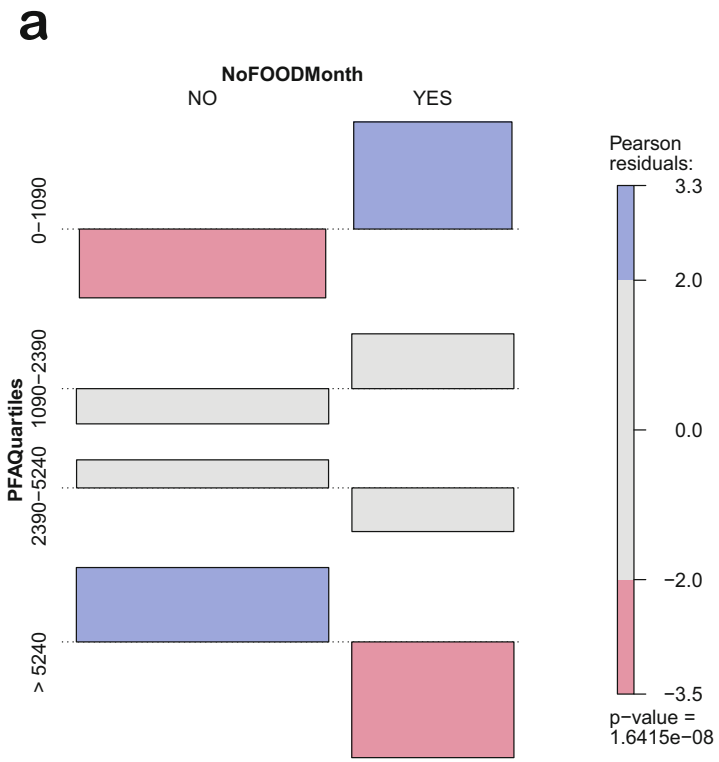

Fig. 5 Pearson residuals visualization after chi-squared test of Potential food availability (PFA) classes vs. food insecurity survey binary questions. a Perception of lack of food in the last month, b Household members going to sleep without eating in the last month. Blue rectangles show

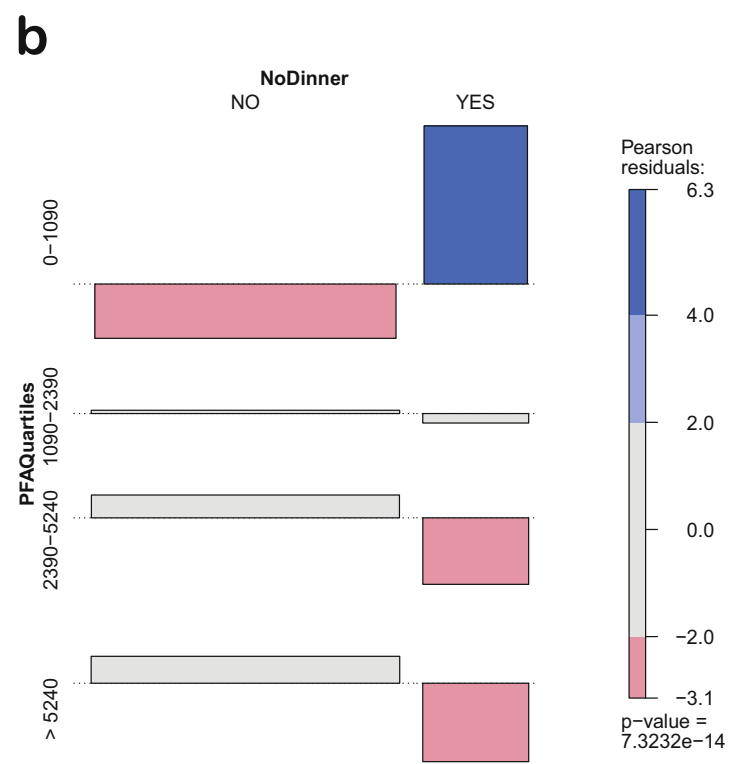

positive significant associations, and red rectangles show negative signif-

icant associations, gray rectangles show non-significant associations

grown crops, with increasing importance of cash crop and decreasing importance of livestock when moving up the quartiles (Fig. 4b).

To test the PFA indicator, we compared the PFA with the results obtained from two binary questions asked in the survey related to lack of food available. The chi-square test showed a significant positive correlation between the questions related to food limitations with the lowest quartile class of the PFA indicator, as well as negative correlation with the highest quartile (Fig. 5). 
Maize is the most important food crop in the WHG. Farm households in the first two PFA classes, given their large food deficiency, will certainly need to use other livelihood activities and income sources that were not captured in the survey, to buy maize. For these two classes, the average annual household deficit to reach the $2500 \mathrm{kcal} /$ day/MAE threshold is $898 \mathrm{~kg}$ maize per year (which is equivalent to $355 \mathrm{USD} /$ year) for the NEFA class, $367 \mathrm{~kg}$ maize per year (equivalent to 145 USD/year) for the REFA class ( 1 Quetzal $=0.13$ USD) (See supplemental material 1).

\subsection{Food security and farm types in the WHG}

When inspecting the proportion of households within each farm type that is food secure or insecure, we found that, in general, the diversified maize and diversified coffee types (DM and DC) and the specialized coffee type (SC), had a larger proportion of potential food secure households with $60 \%, 83 \%$ and $74 \%$ food secure households respectively. They were followed by the Diversified with Other crops (DO) type with $37 \%$ being food secure, the Specialized Maize (SM) farm households with only $21 \%$ and the Homegarden Farm type (HF) with only $11 \%$. Supplemental material 2 shows the same representation of Fig. 4a for each farm type.

Analysis of the Pearson's residuals of a chi-square test showed that DO, SM and NC farm households had significantly higher frequencies in the lowest and second lowest quartile classes of the PFA indicator, while SC, DC and DM had significantly higher probabilities of being in the upper two quartile classes (Fig. 6). This was closely related to the available arable land for the SC, DC and CM farm types that have above average land size and below average number of people to feed with the land available, as opposed to HF, SM, and DO that have below average land available per member of the household (see Table 2).

Each farm type has significantly different sources of potential energy (Fig. 7, Table 2 and supplemental material 2). Homegarden farm households (HF), with nearly no land available, must rely on other sources of food beyond agriculture. In relation to agriculture, they depended mainly on consuming livestock products (29\% of their PFA) and/or selling those (15\%). The importance of livestock to PFA was greater for this type than for the other farm household types. This type of farm household also relied more on selling food crops (14\%).

Farm households diversified with other crops (DO) showed a higher contribution of their own food crops to the PFA than the Home-garden Farm households (HF). This dependency was greater than for both coffee-based farm households (SC and DC), with a value of $49 \%$. The rest of the energy is obtained equally from different sources, with a contribution between $10 \%$ and $21 \%$. The Specialized Maize farm household (SM) type was the one that obtains the highest proportion of energy by consuming own food crops (78\%). In the diversified maize-based farming systems (DM) this value was $58 \%$ while they obtain $30 \%$ of PFA from crop sales, mainly cash crops (24\%) (Fig. 7 and Table 2).

Farm households specialized in coffee (SC), not surprisingly, rely heavily on coffee cash crops $(89 \%)$ with minimum contribution from other sources, while the diversified coffeebased farm households (DC) obtained 52\% of energy from selling their crops (47\% from cash crops and 5\% from sales of food crops). In contrast with the specialized coffee farmers (SC), DC farmers obtain 35\% of their energy from own food crops. Small specialized coffee farmers (SC) got only $6 \%$ of
Fig. 6 Pearson's residuals after a chi-square test between Farm types and Potential food availability (PFA) quartiles. SM: Small scale Specialized Maize farm households, DM: Diversified Maize based farm households, DC: Large Diversified Coffee farm households, DO: Households Diversified with Other crops, HF: Home-garden Farm households, SC: Small scale Specialized Coffee farms. Blue rectangles show positive significant associations, and red rectangles show negative significant associations, gray rectangles show non-significant associations

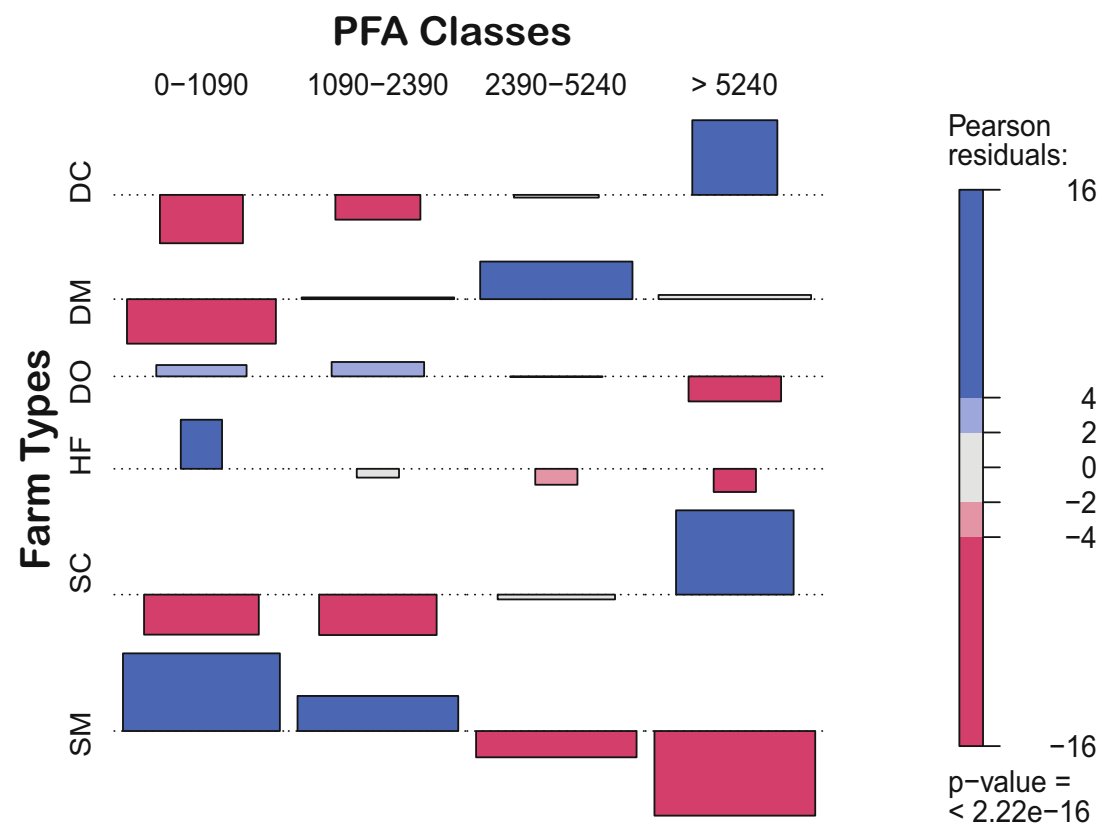




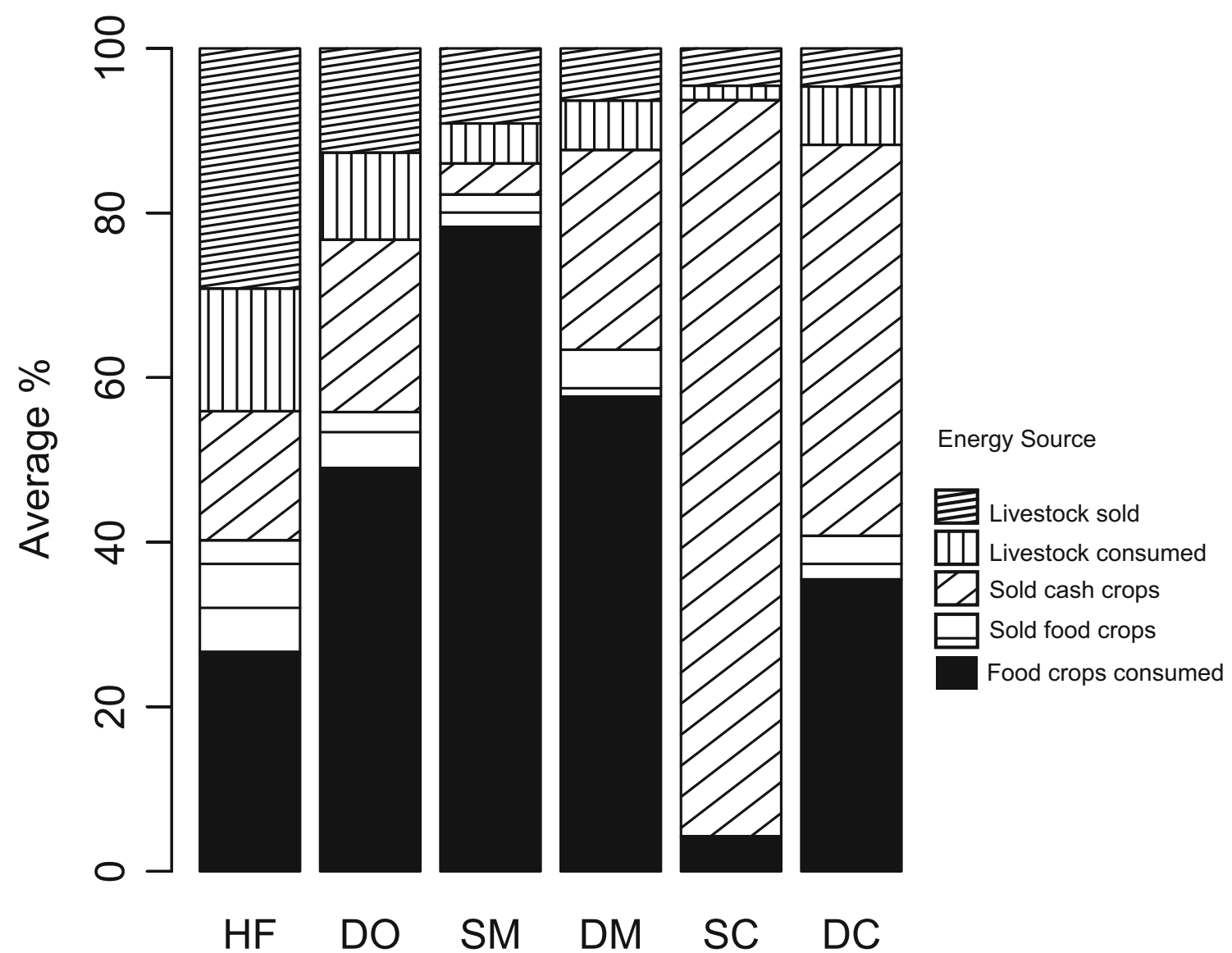

\section{Farm Types}

Fig. 7 Average percent contribution of each source of energy for different farm household types in the Western Highlands of Guatemala. SM: Small scale Specialized Maize farm households, DM: Diversified Maize based farm households, DC: Large Diversified Coffee farm households, DO:

their PFA from livestock while DC households obtain a bigger share of PFA from livestock consumed (7.1\% DC vs $1.8 \%$ SC) and almost the same from livestock sold (around 4.5\%) (Fig. 7 and Table 2).

In the case of maize, the major staple food crop of the region, the direct average contribution to daily PFA was as follows: specialized coffee farmers (SC) had the lowest value of energy derived from maize (3.4\%). Not surprisingly, maize farmers have a larger contribution from maize to PFA, Specialized Maize (SM) reached $75.7 \%$ of their potential energy from maize, and the Diversified Maize (DM) had 53.6\%. The Diversified farmers on other crops (DO) still get a substantial amount of energy from maize, $44.4 \%$. The diversified coffee farmers (DC), although they rely on cash crops for the generation of $52.8 \%$ of their PFA, still obtained $32.9 \%$ from the maize they grow. Finally, the HF type may get only $10.1 \%$ of their energy from maize, but that reached $26.4 \%$ of energy available when potato is included in the share of grown and consumed food crops.
Households Diversified with Other crops, HF: Home-garden Farm households, SC: Small scale Specialized Coffee farms (see also Table 2 and supplemental material 2)

\section{Discussion}

Combining farm household typologies with a simple, yet robust, food security indicator, enables a better understanding of the diversity of farming systems and the potential contribution of agriculture to food security. This is an important step in improving the targeting of agricultural initiatives designed to enhance food security.

\subsection{Targeting alternatives for improved food security}

Our results show the large diversity of farming systems in the WHG region dominated by maize and coffee production, as well as the large differences in terms of their potential food availability (PFA), the indicator we used to approximate food security. In our PFA calculation, $52 \%$ of farm households in the WHG do not have the means to attain sufficient energy from their agricultural activities. 
Farmers with few resources (particularly arable land) and that are either specialized in maize (SM), diversified with other crops (DO) or home-garden farm households (HF), suffer the highest rates of food insecurity. In these cases, $60 \%$ of farm households are unable to match their energy needs from agricultural activities. Only $37 \%$ of the Diversified with Other crops (DO), $21 \%$ of the specialized maize (SM) and only $11 \%$ and the Home-garden Farm households (HF) can be considered food secure from their agricultural activities (Table 2 and Supplemental material 2). In general the diversified types $\mathrm{DM}, \mathrm{DC}$ and the SC, have a larger proportion of potential food secure households with $60 \%, 83 \%$ and $74 \%$ food secure households, respectively. It is important to underline that these farm types have more than average arable land available, while they also have an important focus on cash crops (notably coffee) for their potential food availability. It is also worth noting that coffee production is not an option open to all farmers for a plethora of agro-ecological and socio-economic reasons.

Overall, our results are consistent with other studies on the severity of food insecurity and malnutrition in the WHG. For example, USAID (2018) has estimated that approximately $50 \%$ of Guatemalan children under five years of age are stunted due to chronic food insecurity and, within indigenous areas such as the WHG, nearly $70 \%$ of the population is chronically malnourished. To target those farm households with more acute food insecurity, development interventions need to prioritize farm types of the SM, DO and HF. These farm types are mainly concentrated in the Departments of Quetzaltenango and Totonicapán as well as the Southern Quiche, South and Central Huehuetenango and Northern San Marcos (see Supplemental Material 3).

Understanding better the spatial distribution of different farm households as well as PFA levels would be an important step further in better targeting specific interventions. Adding a spatial layer to the analysis presented here, taking into account socioeconomic aspects such as distance to roads and markets, prices of products and price variability; as well as biophysical ones such as soil types, slope, rainfall levels and primary production potential, would provide support to direct specific development investments to fight food insecurity. For example, comparing two neighboring municipalities in the Huehuetenango department, Chiantla and Aguacatán, shows important differences that supplement the farm typology analyses we performed. Although Chiantla has a large proportion of resource poor farmers (DO and HF) in comparison to Aguacatán, it has a lower proportion of farm households in the most food insecure classes (see Supplemental material 3). This might be due to Chaintla's proximity to Huehuetenango city therefore allowing farmers to have diversified cash crop production and greater off-farm income generating activities. These differences suggest that interventions related to the intensification of the maize production systems would be a better fit in Aguacatán for the improvement of local food security, while improved value chains for vegetables and livestock products might have a better chance of success in Chiantla. In addition to the spatial distribution of farm household types and PFA levels, understanding the spatial and temporal variability of key determinants of food security (e.g. spatiotemporal variation of prices and labor availability and agricultural production potential), might provide better elements for targeting specific interventions.

The consumption of food crops (notably maize) plays a key role in food security of a large part of the farm households in the WHG (Figs. 4 and 7 and Table 2). However, as illustrated by Fig. 4a, the contribution of grown and consumed crops has a bell shape in relation to PFA in which, for very low and very high PFA values, the contribution of consumed food crops is relatively low compared to the middle section of the PFA value range. Similar results have been documented in other studies (Frelat et al. 2016; Ritzema et al. 2017; Lopez-Ridaura et al. 2018) showing a) a common pattern among small scale farming systems in completely different regions of the world; and b) that our approach and analysis is capturing the large diversity of farming systems and livelihoods.

Maize is critical for food security in the WHG and it represents a high percentage of the PFA for most farm households of almost all types. Maize grain yields in the region range from 1 to $2 \mathrm{t}$ per ha (Hellin et al. 2017) and increasing the yield and yield stability of this crop is critical. This would improve food security of farm households in the WHG substantially, especially for those with little arable land available and for which maize is important in their PFA score, for example the SM type of farm households. Participatory breeding and seed exchanges to improve adapted maize landraces for specific agro-ecologies (e.g. van Etten and de Bruin 2007; Smith et al. 2001), improved soil health through soil and water conservation technologies (e.g. Hellin and López-Ridaura 2016) as well as improved use of external and locally available inputs, might represent alternatives to improve the food security of these farm types.

For farmers with relatively more land available, such as the Diversified Maize (DM) and Diversified Coffee (DC) types, for which maize is also key in the food security profile, alternatives to harness the efficiency of diversified systems can be considered. Intercropping and rotations with beans, fruit trees and several other crops relevant for the diet of local people or for the markets (e.g. Turrent-Fernández et al. 2017; RuizMendoza et al. 2012) can represent options to improve the food security of these types of farm households.

Cash crops, especially coffee and vegetables, are important contributions to the food security of farm households in the WHG, notably for the specialized coffee farmers (SC) but also for the diversified coffee, maize and other crop farm households (i.e. DC, DM, DO). Strengthening value chains for these products and improving their resilience to market changes, climatic changes and biological changes (e.g. disease emergence in coffee) is important for improving the food security 
status and reducing poverty of those farm types. Coffee farmers in the region had already experienced prices crashes in the early 2000s and, as Bathfield et al. $(2013,2016)$ pointed out, different strategies were implemented by coffee farmers in the region to cope with the crisis, such as farm and market diversification (e.g. the Cooperativa Guaya'b gathering and commercializing coffee and honey), accessing niche markets such as organic production or, when possible, extending the area under coffee. Additionally, more specific studies on the effect of cash crops and nutrition of rural households in the WHG, have shown that diets and nutrition do not necessarily improve with increased income coming from growing and selling non-traditional export crops (e.g. Méthot and Bennett 2018). Together with strengthening the value chains of these cash crops, education on nutrition and health has to take place.

Livestock is not a major source of energy for rural households in the WHG but, for some farm types such as the HF and DO, two of the types with the highest probability of being food insecure, livestock products either consumed or sold represent more than $20 \%$ of their PFA indicator. For these land constrained farm households, improving disease control and health of livestock, notably poultry, would be a step forward to contribute to their food security (e.g. Wong et al. 2017; de Bruyn et al. 2015).

Capturing the diversity of farming systems through a typology allowed us to identify the main livelihood strategies that farm households in the WHG follow to attain food security and can provide important information for developing and/or adapting technological or policy interventions to help attain zero hunger. Development efforts in the WHG can be mapped to broader typologies that, beyond the static farming characteristics we took into account, also consider, for example, the trajectories of farming systems and the level of aspiration such as suggested by Dorward et al. (2009) and Tittonell (2014) or social identities considering ethnic group, household composition and empowerment of decision making (Camacho-Villa et al. 2018). In our analysis, small scale Specialized Maize farm households and Diversified Maize households (SM and DM) have a significant correlation with indigenous selfdenomination of the respondent (see supplemental material 4).

\subsection{Food security and rural livelihoods}

Food insecurity is a multifaceted and complex phenomenon. In places like the WHG, with a mainly rural population, agriculture contributes importantly to the food security of that region and its farm households. However, with the current high pressure on land availability, other livelihood strategies have been deployed by rural families. Taking into account the importance of migration as well as the urbanization of the WHG, we recognize a weakness in our study, namely that it does not factor in the contribution of off/non-farm income to farm household food security. Remittances and off-farm incomes have been recognized as important sources of food for the small-scale farmers in the WHG (Taylor et al. 2006). Unfortunately, in our data set, off-farm income and remittances were not included so we had to limit our study to the contribution of agriculture to food security and how this contribution varies across farm types. While most of the population in the WHG is rural and agriculture is the backbone of food security in the region, the lack of information on off-farm income and remittances is a major limitation to a full grasp of the food security status in the region.

Moreover, food security is not the only objective of farmers in the WHG as with other small scale farming systems in the world. Income generation, labor productivity, reduction of external input use and monetary costs of production, the preservation of cultural values and other aspects related to the stability, resilience and adaptability of natural resource management systems are, among others, also important features for the assessment of the sustainability of small scale farming systems (Astier et al. 2011). The analysis presented here could serve as the basis but needs to be complemented by an integrated assessment. A broad variety of tools and approaches can be used for this, ranging from participatory assessment to modeling techniques at the farm household level (LopezRidaura et al. 2014; Groot et al. 2012).

The resilience of farmers in the WHG, like their counterparts throughout Latin-America, is underpinned by their participation in multiple forms of economic provisioning that, in turn, enables them to maintain culturally-important practices such as continuing to grow local maize varieties (Barkin 2002). Classical economic theory would suggest that cultivation of low value maize varieties is irrational; however, the maintenance of local maize varieties is a key component of farmers' heritage (Keleman et al. 2013). The reality is that while wage labor and/or export crop production may provide the bulk of their monetary incomes, farmers in the Guatemalan highlands do not necessarily prioritize wage employment over agriculture. As other researchers have observed, the income that rural families earn in the labor market is rarely viewed as a substitute for the agricultural output that is produced with household resources; it is more adequately described as an additional resource (Isakson 2009). This is clearly shown in Fig. 4a, where cash orientation in farming only takes place when the farmers are able to produce enough food for levels of 50-70\% food self-sufficiency.

Other studies of smallholder farming households in economic anthropology similarly underscore that choices, which appear rational from a farmer's perspective may differ from "economically rational" behavior, modeled purely in market terms. Mayer (2002) suggests that peasants in the Peruvian Andes tend to calculate agricultural profits and losses in terms of monetary balances (e.g. flows of cash) as opposed to formally accounting for the value of non-marketed inputs, such as household labor. Farmers may perceive subsistence and commercial activities as separate spheres of the household 
economy. Monetary flows from commercial undertakings may sometimes subsidize subsistence production, and conversely, subsistence activities may enable market participation (de Janvry et al. 1989; Blaikie 1989).

\section{Conclusions}

In this study, we used a large and unique dataset of nearly 5000 farm households to capture and formalize the diversity of livelihood strategies. We established a farm household typology based on systems approaches and assessed the potential food security situation of each typology by means of a simple indicator of Potential Food Availability (PFA). Our results show the large diversity of farming systems in the region dominated by maize and coffee production as well as large differences in terms of their PFA. In our model, 52\% of farm households in the WHG do not have the means to attain sufficient energy (as food) from their agricultural activities. This suggests the importance of off/non-farm sources of income/food.

Our typology of farm households, the PFA analysis and the understanding of the contribution of different agricultural activities to their livelihoods and food security is a useful framework for better targeting development interventions towards combating hunger, poverty and malnutrition. Further work could be directed towards better understanding the spatial distribution of farm types and food insecurity, as well as the role of off-farm income. This would allow for effective targeting of interventions as well as the use of these analyses for scenario assessment on either the plausible effects changes in factors such as climate change and migration, or on the potential impact of alternative technologies such as maize intensification or poultry promotion (Lopez-Ridaura et al. 2018).

Policy makers, researchers and development practitioners might employ the analytical framework presented here in this region, or other regions where household data exists, in order to target interventions. Specifically, in the context of activities from USAID in the WHG, a panel survey is currently being performed and similar analysis with such panel data would allow assessment of progress towards fighting hunger and malnutrition in the WHG. Under common agreement in the WHG that agricultural and human nutrition interventions need to be conducted together, analyses such as the one presented in this paper can provide the analytical framework to design and implement such activities towards the Sustainable Development Goal of ending hunger, achieving food security, improving nutrition and promoting sustainable agriculture.

Acknowledgments We would like to acknowledge data shared and financial support provided by the United States Agency for International Development (USAID) through its Global Hunger and Food Security Initiative, Feed the Future under the "BuenaMilpa" project, as well as the CGIAR Research Program on MAIZE for support provided through the "Panamericana" project. The views and opinions expressed in this article are those of the authors and do not necessarily reflect the position of any agency, funding body or institution. We would also like to thank the five anonymous reviewers for their help to improve the quality and clarity of this article.

\section{Compliance with ethical standards}

Conflict of interest The authors declare that they have no conflict of interest

Open Access This article is distributed under the terms of the Creative Commons Attribution 4.0 International License (http:// creativecommons.org/licenses/by/4.0/), which permits unrestricted use, distribution, and reproduction in any medium, provided you give appropriate credit to the original author(s) and the source, provide a link to the Creative Commons license, and indicate if changes were made.

\section{References}

Alvarez, S., Paas, W., Descheemaeker, K., Tittonell, P., \& Groot, J. C. J. (2014). Constructing typologies, a way to deal with farm diversity: General guidelines for the humid tropics. Report for the CGIAR research program on integrated Systems for the Humid Tropics. Plant Sciences Group, Wageningen University, the Netherlands.

Angeles, G., Hidalgo, E., Molina-Cruz, R., Taylor, T., UrquietaSalomón, J., Calderón C, Fernández, J.C., Hidalgo, M., Brugh, K. \& Romero, M. (2014). Encuesta de Monitoreo y Evaluación del Programa del Altiplano Occidental, Línea de Base 2013. 149 pp. USAID. Resource document. https://www. measureevaluation.org/resources/publications/tr-14-100-es. Accessed December 142017.

Astier, M., Speelman, E. N., López-Ridaura, S., Masera, O. R., \& Gonzalez-Esquivel, C. E. (2011). Sustainability indicators, alternative strategies and trade-offs in peasant agroecosystems: Analysing 15 case studies from Latin America. International Journal of Agricultural Sustainability, 9(3), 409-422.

Barkin, D. (2002). The reconstruction of a modern Mexican peasantry. The Journal of Peasant Studies, 30(1), 73-90.

Bathfield, B., Gasselin, P., López-Ridaura, S., \& Vandame, R. B. M. (2013). A flexibility framework to understand the adaptation of small coffee and honey producers facing market shocks. The Geographical Journal, 179(4), 356-364.

Bathfield, B., Gasselin, P., García-Barrios, L. E., Vandame, R. B. M., \& López-Ridaura, S. (2016). Understanding the long-term strategies of vulnerable small-scale farmers dealing with markets' uncertainty. The Geographical Journal, 182(2), 165-177.

Berre, D., Baudron, F., Kassie, M., Craufurd, P., \& Lopez-Ridaura, S. (2016). Different ways to cut a cake: Comparing expert-based and statistical typologies to target sustainable intensification technologies, a case-study in southern Ethiopia. Experimental Agriculture, 55, 1-17. https://doi.org/10.1017/S0014479716000727.

Blaikie, P. (1989). Explanation and policy in land degradation and rehabilitation for developing countries. Land Degradation and Development, 1(1), 23-37.

de Bruyn, J., Wong, J., Bagnol, B., Pengelly, B., \& Alders, R. (2015). Family poultry production and food and nutrition security. $C A B$ Reviews, 10(13), 1-9.

Camacho-Villa, T.N., Barba-Escoto, L., Burgueño, J., Tickamyer, A., Glenna L. \& López-Ridaura, S. (2018). Diversity of small-scale maize farmers in the Western highlands of Guatemala: Integrating gender into farm typologies. Zooming into the 
diversity of small-scale maize farmers from the Western highlands of Guatemala: Evidencing the importance of integrating a gender dimension to farm typologies. (In Press) in Sachs C. (Editor) Gender Perspectives on Agriculture and Natural Resource Management for Enhanced Rural Prosperity. Routledge

Cattell, R. B. (1966). The scree test for the number of factors. Multivariate Behavioral Research, 1(2), 245-276.

Dorward, A., Anderson, S., Bernal, Y. N., Vera, E. S., Rushton, J., Pattison, J., \& Paz, R. (2009). Hanging in, stepping up and stepping out: Livelihood aspirations and strategies of the poor. Development in Practice, 19(2), 240-247.

van Etten, J., \& de Bruin, S. (2007). Regional and local maize seed exchange and replacement in the western highlands of Guatemala. Plant Genetic Resources, 5(2), 57-70.

FAO. (1996). Food, agriculture and food security: Developments since the world food conference and prospects for the future. World food summit technical background document no. 1. Rome, Italy.

FAO. (2001). Human energy requirements. Food and nutrition technical report series 1 (pp. 1-103). Rome, Italy: Food and Agricultural Organization.

FAO. (2003). Trade reforms and food security, conceptualizing the linkages. Food and agriculture organization of the United Nations. Rome, Italy.

Frelat, R., Lopez-Ridaura, S., Giller, K. E., Herrero, M., Douxchamps, S., Djurfeldt, A. A., Erenstein, O., Henderson, B., Kassie, M., Paul, B. K., Rigolot, C., Ritzema, R. S., Rodriguez, D., van Asten, P. J., \& van Wijk, M. T. (2016). Drivers of household food availability in sub-Saharan Africa based on big data from small farms. Proceedings of the National Academy of Sciences, 113(2), 458-463.

Groot, J. C., Oomen, G. J., \& Rossing, W. A. (2012). Multi-objective optimization and design of farming systems. Agricultural Systems, 110, 63-77.

Hammond, J., Fraval, S., van Etten, J., Suchini, J. G., Mercado, L., Pagella, T., Frelat, R., Lannerstad, M., Douxchamps, S., Teufel, N., Valbuena, D., \& van Wijk, M. T. (2017). The rural household multi-Indicator survey (RHoMIS) for rapid characterisation of households to inform climate smart agriculture interventions: Description and applications in East Africa and Central America. Agricultural Systems, 151, 225-233.

Hartigan, J. A. (1975). Clustering algorithms. John Wiley \& Sons.

Hartigan, J. A., \& Wong, M. A. (1979). Algorithm AS 136: A k-means clustering algorithm. Journal of the Royal Statistical Society. Series C (Applied Statistics), 28(1), 100-108.

Hellin, J., \& López-Ridaura, S. (2016). Soil and water conservation on central American hillsides: If more technologies is the answer, what is the question? AIMS Agriculture and Food, 1(2), 194-207.

Hellin, J., Cox, R., \& Lopez-Ridaura, S. (2017). Maize diversity, market access, and poverty reduction in the Western highlands of Guatemala. Mountain Research and Development, 37(2), 188-197.

IFAD (International Fund for Agricultural Development). (2011). Enabling poor rural people to overcome poverty in Guatemala. Rome Italy. Resource document. https://www.ifad.org/documents/10180/16e68b932e7f-4804-8385-b8d53d784130 Accessed: January 302018.

Isakson, R. S. (2009). No hay ganancia en la milpa: The agrarian question, food sovereignty, and the on-farm conservation of agrobiodiversity in the Guatemalan highlands. Journal of Peasant Studies, 36(4), 725-759.

de Janvry, A., Sadoulet, E., \& Young, L. W. (1989). Land and labour in Latin American agriculture from the 1950s to the 1980s. Journal of Peasant Studies, 16(3), 396-424.

Kassambara, A. (2017). Practical guide to cluster analysis in R: Unsupervised machine learning (Vol. 1). STHDA (statistical tools for high-throughput data analysis, http://www.sthda.com/english/) pp.128-137.
Keleman, A., Hellin, J., \& Flores, D. (2013). Diverse varieties and diverse markets: Scale-related maize "profitability crossover" in the central Mexican highlands. Human Ecology, 41, 683-705.

Lopez-Ridaura, S., Delmotte, S., Le Page, C., Le Quéré, L., Goulevant, G., Chauvelon, P., Sandoz, A., \& Mouret, J. C. (2014). Multi-scale integrated assessment of regional conversion to organic farming (OF). In Organic farming, prototype for sustainable agricultures (pp. 453-478). Dordrecht: Springer.

Lopez-Ridaura, S., Frelat, R., Van Wijk, M. T., Valbuena, D., Krupnik, T. J., \& Jat, M. L. (2018). Climate smart agriculture, farm household typologies and food security: An ex-ante assessment from eastern India. Agricultural Systems, 159, 57-68.

MAGA (Ministerio de Agricultura, Ganadería y Alimentación de la República de Guatemala) (2011). Diagnóstico de la región de occidente de Guatemala. Guatemala City. 106 p.

Mayer, E. (2002). The articulated peasant: Household economies in the Andes. Boulder, CO. USA: Westview Press.

Méthot, J., \& Bennett, E. M. (2018). Reconsidering non-traditional export agriculture and household food security: A case study in rural Guatemala. PLoS One, 13(5), e0198113. https://doi.org/10.1371/ journal.pone.0198113.

R Development Core Team (2018). R: A language and environment for statistical computing. R Foundation for Statistical Computing, Vienna, Austria. ISBN 3-900051-07-0, URL http://www.R-project.org.

Ritzema, R. S., Frelat, R., Douxchamps, S., Silvestri, S., Rufino, M. C., Herrero, M., Giller, K., López-Ridaura, S., Teufel, N., Paul, B., \& Van Wijk, M. T. (2017). Is production intensification likely to make farm households food-adequate? A simple food availability analysis across smallholder farming systems from east and West Africa. Food Security, 9(1), 115-131.

Ruiz-Mendoza, A. D., Jiménez-Sánchez, L., Figueroa-Rodríguez, O. L., \& Morales-Guerra, M. (2012). Adopción del sistema milpa intercalada en árboles frutales por cinco municipios mixes del estado de Oaxaca. Revista Mexicana de Ciencias Agrícolas, 3(8), 1605-1621.

Smith, M. E., Castillo, F. G., \& Gomez, F. (2001). Participatory plant breeding with maize in Mexico and Honduras. Euphytica, 122(3), 551-563.

Steinberg, M., \& Taylor, M. (2008). Guatemala's altos de Chiantla: Changes on the high frontier. Mountain Research and Development, 28(3), 255-262.

Taylor, M. J., Moran-Taylor, M. J., \& Ruiz, D. R. (2006). Land, ethnic, and gender change: Transnational migration and its effects on Guatemalan lives and landscapes. Geoforum, 37(1), 41-61.

Tittonell, P. (2014). Livelihood strategies, resilience and transformability in African agroecosystems. Agricultural Systems, 126, 3-14.

Tittonell, P., Muriuki, A., Shepherd, K. D., Mugendi, D., Kaizzi, K. C., Okeyo, J., Verchot, L., Coe, R., \& Vanlauwe, B. (2010). The diversity of rural livelihoods and their influence on soil fertility in agricultural systems of East Africa-a typology of smallholder farms. Agricultural Systems, 103(2), 83-97.

Turrent-Fernández, A., Cortés Flores, J. I., Espinosa-Calderón, A., Hernández-Romero, E., Camas-Gómez, R., Torres-Zambrano, J. P., \& Zambada-Martínez, A. (2017). MasAgro o MIAF ¿Cuál es la opción para modernizar sustentablemente la agricultura tradicional de México. Revista Mexicana de Ciencias Agrícolas, 8(5), 1169-1185.

USAID (2013). Integration of USAID in the Western highlands. Resource document. http://pdf.usaid.gov/pdf_docs/pdacx493.pdf. Accessed September 272017.

USAID (2018). Food Assistance Fact Sheet Guatemala. Updated January, 2018. Resource document. https://www.usaid.gov/sites/default/ files/documents/1866/FFP_Fact_Sheet_Guatemala.pdf. Accessed January 282018.

USDA (2015). US Department of Agriculture, Agricultural Research Service, nutrient data laboratory. USDA National Nutrient Database for standard reference, release 28 (slightly revised). Version Current: May 2016. Online: http://www.ars.usda.gov/ba/ bhnrc/ndl. Accessed 5 July 2016. 
WFP (World Food Programme). (2018). Guatemala. Country profile. https:// www.wfp.org/node/3475/4323/639382. Accessed May 2018.

Wong, J. T., de Bruyn, J., Bagnol, B., Grieve, H., Li, M., Pym, R., \& Alders, R. G. (2017). Small-scale poultry and food security in resource-poor settings: A review. Global Food Security, 15, 43-52.

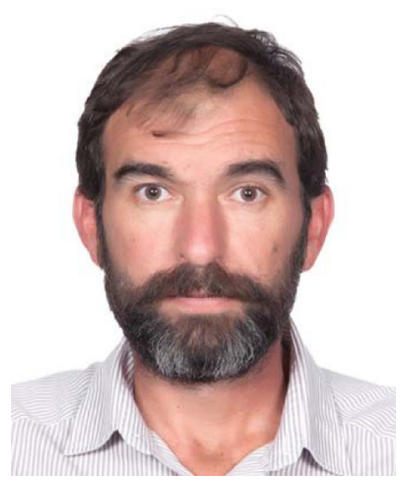

Santiago López-Ridaura is a senior scientist at the Centro Internacional de Mejoramiento de Maiz y Trigo (CIMMYT), based in its headquarters in Mexico. His research interests are the integrated assessment of farming systems and the use of modeling tools to explore scenarios and understand tradeoffs among different objectives. He has over 15 years experience in the development of approaches and tools for farming systems analysis and has worked in developed and developing countries.

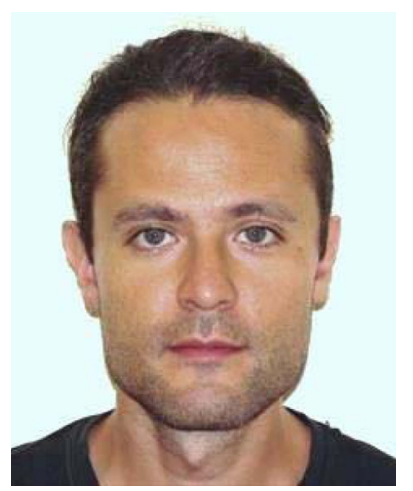

Luis Barba-Escoto holds an MSc in Complexity Sciences. He currently works as a research assistant with the sustainable intensification programs at CIMMYT. There he implements multivariate statistics and machine learning algorithms to develop models for understanding the diversity of farming systems.

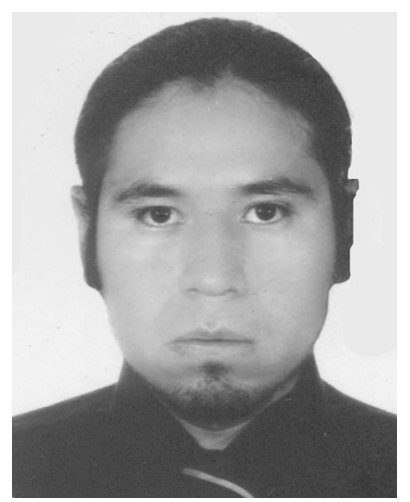

Cristian Reyna is currently pursuing a $\mathrm{PhD}$ on Agricultural and Health Sciences at Universidad Autonoma MetropolitanaXochimilco, Mexico. He works on the development, implementation and assessment of alternatives to improve the sustainability of farming systems in Mexico and Guatemala. He worked as a research assistant at CIMMYT on data aquisition and analysis and has contributed to several publications.

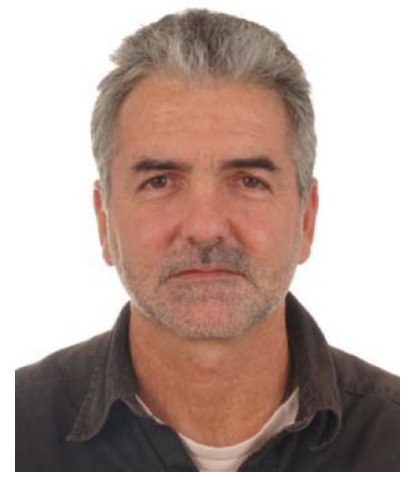

Jon Hellin was a Principal Scientist with CIMMYT, based in its headquarters in Mexico. He is now with the International Rice Research Institute (IRRI) based in the Philippines. He has almost 30 years' agricultural research-for-development experience from Latin America and the Caribbean, SubSaharan Africa and South Asia. His research has focused on climate change adaptation and mitigation, agri-food systems, and agricultural innovation systems. Jon has authored and co-authored two books and 80 articles in peer-reviewed journals.

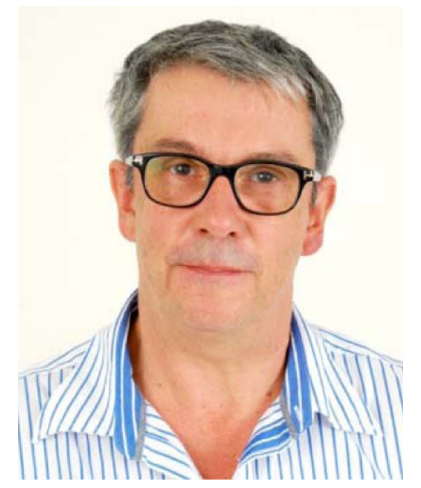

Bruno Gérard is the Director of CIMMYT's Sustainable Intensification Program. He leads a team of over 40 international scientists focusing on sustainable intensification of maize and wheat-based systems in SubSaharan Africa, South Asia and Latin America. Before joining CIMMYT, he worked as a Principal Scientist at ICRISAT and as a System-wide Livestock (SLP) Program coordinator at ILRI. He was trained as an agricultural and irrigation engineer, and holds MSc degrees from the University Catholique de Louvain, Belgium (1987) and Utah State University, USA (1990), and a PhD from the University of Hohenheim, Germany (2000). His research interests include geo-spatial system analysis, research design, soil fertility management at farm and landscape levels, crop-livestock integration in smallholder farming systems, and participatory methods.

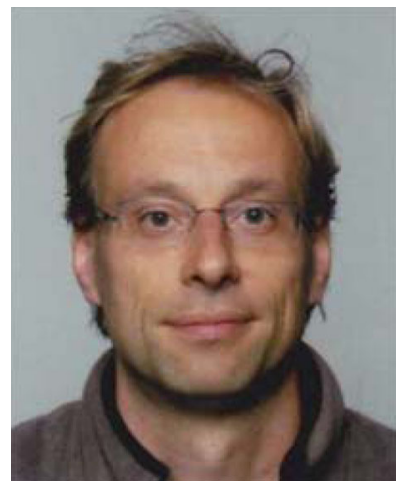

Mark van Wijk is a Senior Scientist at the International Livestock Research Institute (ILRI), based in Quito, Ecuador. His research focuses on analysing farming systems in developing countries, trying to harvest the added value of combining modeling, experimental, participatory and statistical approaches. Previously he worked for almost 10 years as Assistant Professor at Wageningen University in the Plant Production Systems group. He has more than 80 publications in international peer reviewed journals, and has supervised more than 30 MSc and $10 \mathrm{PhD}$ students. 